\title{
Peran satuan pemeriksaan internal untuk mewujudkan good university governance dengan audit kepatuhan sebagai variable moderating
}

\author{
Alfuzanni ${ }^{*} 1$ \& Nasrullah Djamil² \\ ${ }^{1}$ Universitas Riau, Indonesia \\ 2Universitas Islam Negeri Sultan Syarif Kasim Riau, Indonesia
}

\begin{abstract}
Abstrak Penelitian ini bertujuan untuk menguji dan memberikan bukti empiris tentang sejauh mana peran Satuan Pemeriksaan Internal Untuk Mewujudkan Good University Governance dengan Audit Kepatuhan Sebagai Variabel Moderating Pada Perguruan Tinggi Berstatus Badan Layanan Umum di Provinsi Riau dan Sumatera Barat. Penelitian ini merupakan penelitian kuantitatif. Sampel yang digunakan sebanyak 34 auditor internal. Hasil Penelitian menyimpulkan bahwa Variabel Satuan Pemeriksaan Internal dan Audit Kepatuhan secara bersama-sama atau secara simultan berpengaruh terhadap Terwujudnya Good University Governance.
\end{abstract}

Kata kunci: satuan pemeriksaan internal; good university governance; audit kepatuhan

\begin{abstract}
This study aims to examine and provide empirical evidence about the extent of the role of the Internal Audit Unit to Achieve Good University Governance with Compliance Audit as a Moderating Variable in Higher Education Status Public Service Agencies in Riau and West Sumatra Provinces. This research is a quantitative research. The sample used was 34 internal auditors. The results of the study concluded that the Internal Audit Unit and the Compliance Audit Unit jointly or simultaneously affected the Realization of Good University Governance.
\end{abstract}

Keywords: internal audit unit; good university governance; compliance audit

JEL Classification: $M 41 ; M 42 ; M 48$ 


\section{PENDAHULUAN}

Perguruan Tinggi merupakan lembaga pendidikan tertinggi yang memberikan pelayanan bagi masyarakat untuk memperoleh pendidikan. Perguruan tinggi sebagai lembaga yang memberikan pelayanan di bidang pendidikan berdasarkan mandat akademik dari pemerintah mesti mampu melaksanakan pelayanan pendidikan yang bermutu dengan tata kelola yang baik, sebab perguruan tinggi memiliki peran besar terhadap kemajuan sebuah Negara.

Tata kelola yang baik menjadi hal yang sangat penting bagi perguruan tinggi dikarenakan perguruan tinggi merupakan perpanjangan tangan pemerintah dalam memberikan pelayanan kepada masyarakat dibidang pendidikan. Tata kelola yang baik bagi perguruan tinggi tersebut lebih dikenal dengan Good University Governance (GUG). Good University Governance merupakan konsep tata kelola perguruan tinggi yang berlaku sejak tahun 2005.

Menurut Wijatno (2009), secara sederhana Good University Governance dapat dipandang sebagai penerapan prinsip-prinsip dasar konsep "good governance"dalam sistem dan proses governancepada institusi perguruan tinggi melalui berbagai penyesuaian yang dilakukan berdasarkan nilai-nilai yang harus dijunjung tinggi dalam penyelenggaraan perguruan tinggi secara khusus dan pendidikan secara umum. Kemudian ia juga mengemukakan bahwa terdapat lima prinsip Good University Governance yaitu transparansi, akuntabilitas, responsibilitas, independensi, dan keadilan. Sedangkan menurut Rahmania dalam Forest dan Altbach (2007) Good University Governance merupakan dasar penyelenggaraan seluruh aktivitas pendidikan pada perguruan tinggi. Oleh karena itu untuk mencapai Good University Governance perguruan tinggi harus mampu melaksanakan peran dan tanggungjawabnya sesuai aturan yang diberlakukan dalam Undang-Undang yang mengatur pola PK-BLU.

Selain itu, United National Development Program (1997) mendefinisikan governance sebagai penggunaan wewenang ekonomi, politik dan administrasi guna mengelola urusan-urusan negara pada semua tingkat. Tata pemerintahan mencakup seluruh mekanisme, proses dan lembaga-lembaga dimana warga dan kelompok-kelompok masyarakat mengutarakan kepentingan mereka, menggunakan hak hukum, mematuhi kewajiban dan menjembatani perbedaan-perbedaan diantara mereka Selanjutnya ditinjau dari arti kata secara harfiah Good Governance, maka good adalah baik, sedangkan governance adalah pemerintahan, sehingga secara sederhana diartikan pemerintahan yang baik yang bebas dari praktik Korupsi, Kolusi dan Nepotisme (KKN) (Astuti, 2010).

Prinsip-prinsip Good Governance menurut Wijatno (2009) terdapat lima prinsip yaitu Transparansi (transparency), Akuntabilitas (accountability), Responsibilitas (responsibility), Independensi (independency), dan Keadilan (fairness).

Good University Governance bagi perguruan tinggi menjadi tujuan yang harus mampu diwujudkan. Hal tersebut menjadi sebuah kewajiban pokok semenjak perguruan tinggi resmi menjadi Badan Layanan Umum (BLU) berdasarkan UndangUndang Nomor 1 Tahun 2004 Tentang Perbendaharaan Negara, dimana pemerintah memperkenalkan pola BLU bagi satker yang menyediakan layanan kepada masyarakat. BLU secara khusus diatur dalam pasal 68 dan 69 dimana instansi pemerintahan yang tugas pokok dan fungsinya memberi pelayanan kepada masyarakat dapat menerapkan pola pengelolaan keuangan yang fleksibel dengan menonjolkan produktivitas, efesiensi, dan efektivitas. BLU dibentuk untuk 
meningkatkan pelayanan kepada masyarakat dalam rangka memajukan kesejahteraan dan mencerdaskan kehidupan bangsa.

Peraturan Pemerintah Republik Indonesia Nomor 23 tahun 2005 pasal 1 ayat 1 , menjelaskan tentang Badan Layanan Umum, yang selanjutnya disebut adalah instansi di lingkungan Pemerintah yang dibentuk untuk memberikan pelayanan kepada masyarakat berupa penyediaan barang dan/atau jasa yang dijual tanpa mengutamakan mencari keuntungan dan dalam melakukan kegiatannya didasarkan pada prinsip efisiensi dan produktivitas.

Satuan Pengawasan Internal merupakan auditor internal dalam suatu perguruan tinggi yang tugas dan fungsinya untuk senantiasa mengevaluasi hasil kinerja keuangan perguruan tinggi, mengawasi setiap kebijakan manajemen dan melaporkan hasil evaluasi dan pengawasan tersebut kepada pimpinan. Satuan pengawasan internal merupakan pengawasan manajemen yang fungsinya mengukur dan mengevaluasi sistem pengendalian dengan tujuan membantu semua anggota manajemen dalam mengelola secara efektif pertanggungjawaban dengan cara menyediakan analisis, rekomendasi, dan komentar-komentar yang berhubungan dengan kegiatan-kegiatan yang telah ditelaah (Sitompul, 2004).

Untuk tercapainya Good University Governance bagi perguruan tinggi, maka peran Sistem Pengendalian Internal atau disebut Satuan Pengawasan Internal (SPI) menjadi salah satu faktor penentu yang paling penting. Dimana Satuan Pengawasan Internal merupakan auditor internal dalam suatu perguruan tinggi yang tugas dan fungsinya untuk senantiasa mengevaluasi hasil kinerja keuangan perguruan tinggi, mengawasi setiap kebijakan manajemen dan melaporkan hasil evaluasi dan pengawasan tersebut kepada pimpinan. Audit Internal adalah audit yang dilakukan oleh unit pemeriksa yang merupakan bagian dari organisasi yang diawasi (Mardiasmo, 2005).

Sistem Pengendalian Internal tersebut berada langsung dibawah pimpinan perguruan tinggi yang disebut Satuan Pengawasan Internal. Hal tersebut sesuai yang tercantum dalam PP Nomor 23 tahun 2005 pasal 35 ayat 1 yang menyebutkan bahwa pemeriksaan internal Badan Layanan Umum atau perguruan tinggi dilaksanakan oleh Satuan Pemeriksaan Internal yang merupakan unit kerja yang berkedudukan langsung di bawah pemimpin Badan Layanan Umum.

Selanjutnya, Satuan Pengawasan Internal dalam melaksanakan tugas dan fungsinya sebagai auditor internal pada perguruan tinggi dalam mencapai tujuan pengawasan tersebut, maka salah satu faktor yang mesti diperhatikan adalah kepatuhan dari pihak yang di audit terhadap peraturan perundangan atau prosedur audit yang telah ditetapkan. Kepatuhan pihak yang di audit atau disebut dengan Audit Kepatuhan adalah proses kerja yang menentukan apakah pihak yang diaudit telah mengikuti prosedur, standar, dan aturan tertentu yang ditetapkan oleh pihak yang berwenang. Dalam hal ini auditor internal memastikan apakah proses kerja yang dilakukan sudah sesuai dengan prosedur, standar, dan aturan tertentu tersebut.

Audit Kepatuhan adalah proses kerja yang menentukan apakah pihak yang diaudit telah mengikuti prosedur, standar, dan aturan tertentu yang ditetapkan oleh pihak yang berwenang. Dalam hal ini auditor internal memastikan apakah proses kerja yang dilakukan sudah sesuai dengan prosedur, standar, dan aturan tertentu tersebut. Kumaat (2011) menjelaskan Audit Kepatuhan adalah audit yang bertujuan memberi gambaran mengenai efektivitas implementasi atau pelaksaan sistem kerja (Business Process) yang berlaku dalam seluruh aktivitas korporasi. Audit kepatuhan merupakan cara yang paling efektif dalam misi membangun pengendalian internal 
(Built In Control) yang kuat Kumaat (2011). Audit Kepatuhan adalah audit yang bertujuan memberi gambaran mengenai efektivitas implementasi atau pelaksaan sistem kerja (Business Process) yang berlaku dalam seluruh aktivitas korporasi. Subjek dari Audit Kepatuhan adalah pihak pelaksana proses (SDM atau Unit Kerja), dimana perlu dipastikan apakah para pelaksana (person/unit in charge) telah mengetahui/mempelajari sistem yang berlaku terkait pekerjaannya, memiliki pemahaman yang benar terhadap sistem yang diketahuinya, memiliki keterampilan yang memadai sebagai pelaksana sistem, memiliki sumber daya/fasilitas pendukung yang memadai untuk pelaksana sistem, dan menjalankan sistem sebagaimana mestinya.

Pada penelitian ini teori yang digunakan sebagai landasan dasar merujuk kepada dua teori yaitu teori agensi dan juga teori stewardship. Teori agency (keagenan) merupakan teori utama (grand theory) atas pemanfaatan jasa Satuan Pengawas Internal oleh instansi. Teori ini berkaitan tentang peran audit eksternal yang dikembangkan oleh Jansen dan Meckling (1976). la menjelaskan bahwa terdapat perbedaan kepentingan antara pihak manajemen (agent) dengan pemegang saham (shareholders), hal itu menimbulkan konflik dimana konflik tersebut menjadi pemicu perhatian bagi pihak manajemen. Teori tersebut menjelaskan bahwa terdapat perbedaan kepentingan antara pihak manajemen dengan para shareholders, hal itu membuat Satuan Pengawas Internal memiliki peran besar dan penting bagi instansi Badan Layanan Umum .

Teori agency mendapat respons yang begitu antusias karena dipandang lebih mencerminkan kenyataan yang ada (Wolfensohn, 1999). Sebab pada kenyataan yang terjadi di lapangan, memang pihak manajemen BLU kurang dipercaya oleh stakeholder, hal tersebut karena terjadinya benturan-benturan kepentingan sebagaimana telah dijelaskan di atas. Pihak manajemen BLU selama ini cenderung hanya memperlihatkan kondisi yang baik-baik saja dalam instansinya. Oleh karena itu, teori agency mempertegas pelaksanaan GUG yang memerlukan peranan SPI secara kontinyu dan komprehensif. Dengan begitu, teori ini dapat dianggap lebih relevan antara variabel yang digunakan di dalam penelitian ini.

Penelitian ini merupakan replikasi dari penelitian Puspitasari (2012) yang berjudul Peran Satuan Pengawasan Internal dalam Pencapaian Good University Governance pada Perguruan Tinggi Berstatus PK-BLU. Hasil penelitian tersebut menunjukkan bahwa SPI berperan positif dalam pencapain GUG. Semakin baik peran SPI maka akan semakin baik pula pencapain GUG. Saran dari Noviana bahwa peneliti selanjutnya dapat menambah variabel lain sebagai variabel independen maupun variabel moderating.

Perbedaan penelitian kali ini dengan penelitian sebelumnya ialah dalam menggunakan sampel, dimana penelitian sebelumnya menggunakan sampel perguruan tinggi se-Jawa yang berstatus PK-BLU, sedangkan pada penelitian kali ini peneliti mencoba menggunakan sampel pada perguruan tinggi se-Sumatera yang berstatus PK-BLU. Dalam penelitian ini juga peneliti menambahkan audit kepatuhan sebagai variabel moderating. Hal tersebut dilakukan untuk mendapatkan hasil berbeda pula.

\section{METODE}

Penelitian ini dilakukan di Sumatera di Provinsi Riau dan Sumatera Barat. Penelitian ini merupakan jenis penelitian kuantitatif. Metode penelitian kuantitatif digunakan untuk meneliti pada populasi atau sampel tertentu, teknik pengambilan 
sampel dilakukan secara penuh dari seluruh populasi yang diteliti, pengumpulan data menggunakan instrumen penelitian, analisis data bersifat kuantitatif atau statistik dengan tujuan untuk menguji hipotesis yang telah ditetapkan (Sugiyono, 2012).

Sumber data yang digunakan yaitu data primer. Data primer adalah sumber data penelitian yang diperoleh langsung dari sumber asli (tidak melalui media perantara) untuk menjawab pertanyaan penelitian. Data primer dikumpulkan dengan menggunakan metode survey melalui penyebaran kuisioner kepada responden (Indriantoro \& Supomo, 2011). Metode pengumpulan data yang dilakukan adalah metode survei (survey methods), tinjauan kepustakaan (library research), dan mengakses website dan situs-situs.

Dalam metode analisis data, penelitian ini menggunakan skala likert 5 poin untuk mengetahui tingkat setuju atau tidak setuju setiap masing-masing responden terhadap pernyataan yang terdapat dalam kuesioner yang berkaitan dengan variabel penelitian. Semua item pernyataan diukur dengan menggunakan skala interval (likert), 1 sampai 5. Jawaban yang didapat akan dibuat skor yaitu: nilai (1) sangat tidak setuju, (2) tidak setuju, (3) netral, (4) setuju, dan (5) sangat setuju. Data penelitian yang dihasilkan oleh oleh skala semantic diferential dan skala likert 5 poin adalah interval (Sugiyono, 2010).

Metode yang digunakan yaitu dengan pengujian Kualitas Data, pengujian Asumsi Klasik, analisis hasil Multiple Regression Analysis (MRA), serta pengujian secara simultan dan uji determinasi $R$ pengaruh variabel independen terhadap variabel dependen dan variabel moderasi secara rinci sesuai dengan prosedur pengolahan data.

Populasi penelitian ini adalah auditor internal (akuntan yang bekerja di Satuan Pemeriksa Internal pada Perguruan Tinggi yang berstatus Badan Layanan Umum) di Provinsi Riau dan Sumatera Barat yang berjumlah 41 orang. Jumlah kuisioner yang terkumpul adalah 34 kuisioner dan dapat memenuhi syarat untuk diolah. Tingkat pengumpulan kuisioner dapat dilihat pada Tabel 1.

Tabel 1. Tingkat Pengumpulan Kuisioner

\begin{tabular}{clcc}
\hline No & Keterangan & Jumlah & Persentase \\
\hline 1 & Total kuisioner yang disebarkan. & 41 & $100 \%$ \\
2 & Total kuisioner yang terkumpul kembali. & 34 & $82,93 \%$ \\
3 & Total kuisioner yang tidak terkumpul kembali. & 7 & $17,07 \%$ \\
\hline & Total kuisioner yang dapat diolah. & 34 & $82,93 \%$ \\
\hline
\end{tabular}

\section{HASIL DAN PEMBAHASAN}

\section{Statistik Deskriptif}

Statistik deskriptif dalam penelitian pada dasarnya merupakan proses transformasi data penelitian dalam bentuk tabulasi sehingga bisa dipahami dan diinterpretasikan. Tabulasi menyajikan ringkasan pengaturan atau penyusunan data dalam bentuk tabel numerik. Statistik deskriptif umumnya digunakan dalam penelitian untuk memberikan informasi mengenai karakteristik variabel peneliti yang paling lama dan data demografi responden. Statistik deskriptif merupakan bentuk gambaran atau deskripsi tentang suatu data, seperti nilai rata-rata, standar deviasi, 
maksimum dan minimum (Ghozali, 2013). Statistik deskriptif dalam penelitian ini dapat dilihat pada Tabel 2.

Tabel 2. Descriptive Statistics

\begin{tabular}{lccccc}
\hline & N & Minimum & Maximum & Mean & Std. Deviation \\
\hline Satuan Pemeriksa Internal & 34 & 67 & 100 & 88.00 & 7.463 \\
Audit Kepatuhan & 34 & 31 & 66 & 54.53 & 7.533 \\
$\begin{array}{l}\text { Good University } \\
\text { Governance }\end{array}$ & 34 & 25 & 54 & 39.24 & 7.046 \\
\hline Valid N (listwise) & 34 & & & & \\
\hline
\end{tabular}

\section{Uji Hipotesis}

\section{Multiple Regression Analysis (MRA)}

Metode Moderated Regression Analisis (MRA) dengan uji interaksi ini digunakan karena penelitian ini pada dasarnya eksistensi dari metode regresi dalam analisis bivariate yang umumnya digunakan untuk menguji pengaruh dua variabel atau lebih variabel independen terhadap variabel dependen dengan skala pengukuran interval dalam suatu persamaan linier. Fokusnya adalah pada pengaruh interaksi dan pengaruh peran yang ada dalam persamaan tersebut. Dengan adanya uji MRA pada penelitian ini diharapkan dapat diketahui pengaruh variabel moderasi terhadap hubungan antara variabel dependen dan variabel indenpenden sesuai hasil uji dari Tabel 3.

Tabel 3. Hasil Uji Pertama Multiple Regression Analysis (MRA)

\begin{tabular}{llrrr}
\hline \multicolumn{5}{c}{ Model Summary } \\
\hline Model & $\mathrm{R}$ & R Square & Adjusted R Square & Std. Error of the Estimate \\
\hline 1 & $.273^{\mathrm{a}}$ & .074 & .045 & 6.884
\end{tabular}

a. Predictors: (Constant), $X 1$

\begin{tabular}{llrr}
\hline & & \multicolumn{3}{c}{ Unstandardized Coefficients } \\
\cline { 3 - 4 } Model & & B & Std. Error \\
\hline 1 & (Constant) & 16.589 & 14.179 \\
& X1 & .257 & .161 \\
\hline
\end{tabular}

a. Dependent Variable: $Y$

Dari hasil Uji pertama MRA di atas didapatkan model persamaan MRA sebagai berikut:

$$
\begin{aligned}
& Y=\alpha+\beta 1 X 1+e \\
& Y=16,589+0,257 X 1+e \\
& \text { Nilai } R \text {-Square }=0,074
\end{aligned}
$$

Kemudian dilanjutkan dengan pengujian kedua MRA. Dimana pada pengujian kedua ini menyertakan pengujian variabel X1 dan X2. Hasil uji kedua MRA dapat dilihat pada Tabel 4. 
Tabel 4. Hasil Uji Kedua Multiple Regression Analysis (MRA)

\begin{tabular}{llllrl}
\hline \multicolumn{5}{c}{ Model Summary } \\
\hline Model & $\mathrm{R}$ & $\mathrm{R}$ Square & Adjusted R Square & Std. Error of the Estimate \\
\hline 1 & $.728^{\mathrm{a}}$ & .529 & & .482 & 5.069 \\
\hline a. Predictors: (Constant), X1, X2, X1, X2 & &
\end{tabular}

\begin{tabular}{llrr}
\hline & & \multicolumn{3}{c}{ Unstandardized Coefficients } \\
\cline { 3 - 5 } Model & & B & Std. Error \\
\hline 1 & (Constant) & 161.509 & 48.334 \\
& X1 & -1.987 & .617 \\
& X2 & -2.349 & .987 \\
& X1X2 & .037 & .012 \\
\hline
\end{tabular}

a. Dependent Variable: $Y$

Dari hasil Uji kedua MRA pada Tabel 4 didapatkan model persamaan MRA sebagai berikut:

$$
\begin{aligned}
& Y=\alpha+\beta 1 X 1+\beta 2 X 2+\beta 3 X 1 X 2+e \\
& Y=161,509+(-1,987 X 1)+(-2,349 X 2)+0,037 X 1 X 2+e \\
& \text { Nilai } R \text {-Square }=0,529
\end{aligned}
$$

Dari keterangan di atas nilai $R$-Square pada regresi pertama sebesar 0,074 atau $7,4 \%$, sedangkan setelah ada persamaan regresi kedua nilai $R$-Square naik menjadi 0,529 atau $53 \%$. Dengan melihat hasil di atas dapat disimpulkan bahwa dengan adanya Audit Kepatuhan (variabel moderasi) akan dapat memperkuat hubungan Satuan Pemeriksaan Internal terhadap Good University Governance.

\section{Koefisien Determinasi (Adjusted R-Square)}

Pengujian ini dilakukan untuk mengetahui seberapa besar keterikatan atau keeratan variabel untuk variabel dependen kualitas audit dengan variabel independen yaitu persaingan jasa, etika bisnis dan skeptisme profesional. Dalam persamaan regresi yang menggunakan lebih dari satu variabel independen, maka nilai $R$-Square yang digunakan untuk menjelaskan persamaan regresi koefisien determinasi yang disesuaikan karena telah memperhitungkan jumlah variabel independen dalam suatu model regresi. Hasil uji koefisien determinasi dapat dilihat pada kolom $R$-Square, yang tampilkan pada Tabel 5 .

Tabel 5. Hasil Uji Koefisien Determinasi

\begin{tabular}{ccccc}
\hline \multicolumn{5}{c}{ Model Summary $^{\mathrm{b}}$} \\
\hline Model & $\mathrm{R}$ & $\mathrm{R}$ Square & Adjusted R Square & Std. Error of the Estimate \\
\hline 1 & $.617^{\mathrm{a}}$ & .381 & .341 & 5.720
\end{tabular}

a. Predictors: (Constant), AKP, SPI

b. Dependent Variable: GUG

Berdasarkan tabel hasil uji koefisien determinasi 4.4.2 diatas dapat diketahui nilai $R$ squared sebesar 0,381 atau jika dijadikan dalam bentuk persen adalah sebesar 38\%. Artinya adalah bahwa variabel Good University Governance (Y) yang dapat dijelaskan oleh variabel Peran Satuan Pengawasan Internal (X1), Audit 
Kepatuhan (X2) adalah sebesar 38\%. Sedangkan sisanya sebesar $62 \%$ dipengaruhi oleh variabel lain yang tidak termasuk kedalam model regresi ini seperti keahlian, integritas, independensi dan lain sebagainya.

\section{Statistik F (Simultan)}

Analisis regresi dengan menggunakan metode uji $\mathrm{F}$ dengan tarif signifikansi $5 \%$ adalah untuk mengetahui pengaruh dari seluruh variabel independen secara bersama-sama atau secara simultan terhadap variabel dependen. Jika nilai $F$ hitung lebih besar lebih besar dari nilai $\mathrm{F}$ tabel, maka Ho ditolak dan Ha diterima dan jika sebaliknya maka $\mathrm{Ho}$ diterima dan $\mathrm{Ha}$ ditolak ataupun dengan melihat nilai probabilitas, jika nilainya kecil dari 0,05 maka Ho ditolak dan Ha diterima dan jika sebaliknya maka $\mathrm{Ho}$ diterima dan $\mathrm{Ha}$ ditolak. Berikut hasil pengujian secara simultan (uji F).

Tabel 6. Hasil Uji Simultan (Uji F)

\begin{tabular}{|c|c|c|c|c|c|c|}
\hline \multicolumn{7}{|c|}{ ANOVA $^{b}$} \\
\hline & Model & $\begin{array}{l}\text { Sum of } \\
\text { Squares }\end{array}$ & df & Mean Square & $\mathrm{F}$ & Sig. \\
\hline \multirow{3}{*}{1} & Regression & 623.979 & 2 & 311.989 & 9.537 & $.001^{a}$ \\
\hline & Residual & 1014.139 & 31 & 32.714 & & \\
\hline & Total & 1638.118 & 33 & & & \\
\hline
\end{tabular}

a. Predictors: (Constant), AKP, SPI

b. Dependent Variable: GUG

Berdasarkan hasil uji simultan (uji f) dapat diketahui $F$ hitung sebesar 9,537 dengan signifikansi $0,001^{\mathrm{a}}$. $\mathrm{F}$ tabel dapat diperoleh dengan perhitungan sebagai berikut:

$$
\begin{aligned}
\mathrm{df} 1 & =\mathrm{k}-1 \\
& =3-1 \\
& =2 \\
\mathrm{df} 2 & =\mathrm{n}-\mathrm{k} \\
& =34-3 \\
& =31 \\
\mathrm{~F} \text { tabel } & =\mathrm{df} 1: \mathrm{df} 2 \\
& =2: 31 \\
& =3,3
\end{aligned}
$$

Keterangan:
n: jumlah sampel
k: jumlah variabel bebas
1: konstan

Dengan demikian, dapat diketahui $F$ hitung $(9,537)>F$ tabel $(3,30)$ dengan Sig. $(0,001)<0,05$. Artinya adalah bahwa variabel independen Satuan Pemeriksaan Internal dan Audit Kepatuhan secara bersama-sama atau secara simultan berpengaruh signifikan terhadap variabel dependen Good University Governance. 


\section{Bukti Empiris}

Hasil pengujian hipotesis 1 mengenai peran Satuan Pemeriksaan Internal terhadap terwujudnya Good University Governance yang mana diperoleh nilai $R$ Square sebesar 0,074 atau 7,4\%. Dengan demikian, peran Satuan Pemeriksaan Internal berpengaruh hanya sebesar $7,4 \%$ terhadap terwujudnya Good University Governance. Sedangkan berdasarkan rumus yang telah ditentukan yaitu:

$$
\begin{aligned}
& Y=\alpha+\beta 1 X 1+e \\
& Y=16,589+0,257 X 1+e
\end{aligned}
$$

Dari persamaan rumus di atas dapat dijabarkan sebagai berikut:

a. Nilai Konstanta $(\alpha)$ sebesar 16,589. Artinya apabila persepsi terhadap variabel independent diasumsikan nol (0), maka variabel Good University Governance bernilai 16,589.

b. Nilai Koefisien variabel Satuan Pemeriksaan Internal sebesar 0,257. artinya bahwa setiap peningkatan Satuan Pemeriksaan Internal sebesar 1 satuan maka akan meningkatkan Good University Governance sebesar 0,257 dengan asumsi variabel yang berhubungan tetap.

c. Standar Error (e) merupakan variabel acak dan mempunyai distribusi probabilitas yang mewakili semua faktor yang mempunyai pengaruh terhadap $Y$ tetapi tidak dimasukkan dalam persamaan.

Penelitian ini sejalan dengan hasil penelitian yang telah dilakukan oleh Sukirman (2011), dan Puspitasari (2012) yang mengemukakan bahwa auditor internal memiliki peran yang cukup besar dalam upaya pencapaian Good University Governance dalam suatu institusi pendidikan.

Hasil pengujian hipotesis 2 mengenai Peran Satuan Pemeriksaan Internal Berpengaruh Terhadap Terwujudnya Good University Governance dengan Audit Kepatuhan Sebagai Variabel Moderasi yang mana diperolehs $R$-Square sebesar 0,529 atau $53 \%$. Dengan melihat hasil di tersebut dapat disimpulkan bahwa dengan adanya Audit Kepatuhan (variabel moderasi) akan dapat memperkuat hubungan Satuan Pemeriksaan Internal terhadap Good University Governance sebesar 53\%. Sedangkan berdasarkan rumus yang telah ditentukan sebagai berikut:

$$
\begin{aligned}
& Y=\alpha+\beta 1 X 1+\beta 2 X 2+\beta 3 \times 1 X 2+e \\
& Y=161,509+(-1,987 X 1)+(-2,349 X 2)+0,037 X 1 X 2+e
\end{aligned}
$$

Dari persamaan rumus di atas dapat dijabarkan sebagai berikut:

a. Nilai Konstanta $(\alpha)$ sebesar 161,509 . Artinya apabila persepsi terhadap variabel independent diasumsikan nol (0), maka variabel Good University Governance bernilai 161,509 .

b. Nilai Koefisien variabel Satuan Pemeriksaan Internal sebesar -1,987. Artinya bahwa setiap peningkatan Satuan Pemeriksaan Internal sebesar 1 satuan maka akan mengalami penurunan Good University Governance sebesar -1,987 dengan asumsi variabel yang berhubungan tetap.

c. Nilai Koefisien variabel Audit Kepatuhan sebesar -2,349. Artinya bahwa setiap peningkatan Audit Kepatuhan sebesar 1 satuan maka akan mengalami penurunan Good University Governance sebesar -2,349 dengan asumsi variabel yang berhubungan tetap. 
d. Nilai Koefisien variabel Satuan Pemeriksaan Internal dan Audit Kepatuhan sebesar 0,037. Artinya bahwa setiap peningkatan Satuan Pemeriksaan Internal dan Audit Kepatuhan sebesar 1 satuan maka akan mengalami kenaikan Good University Governance sebesar 0,037 dengan asumsi variabel yang berhubungan tetap.

e. Standar Error (e) merupakan variabel acak dan mempunyai distribusi probabilitas yang mewakili semua faktor yang mempunyai pengaruh terhadap $Y$ tetapi tidak dimasukkan dalam persamaan.

Hasil penelitian ini menunjukkan bahwa dengan menambah variabel Audit Kepatuhan sebagai variabel moderasi terdapat peningkatan persentase yang signifikan terhadap Good University Governance sebesar 53\% atas saran penelitian sebelumnya. Yang mana hasil penelitian ini tidak dapat dibandingkan dengan penelitian lain atau penelitian sebelumnya, hal tersebut disebabkan belum ditemukan atau tidak adanya penelitian yang memiliki kesamaan dengan penelitian ini.

\section{KESIMPULAN}

Penelitian ini bertujuan untuk mengetahui Peran Satuan Pemeriksaan Internal dan Audit Kepatuhan terhadap Terwujudnya Good University Governance pada Perguruan Tinggi Berstatus PK-BLU di Provinsi Riau dan Sumatera Barat. Berdasarkan data yang telah dikumpulkan maupun pengujian yang dilakukan, maka dapat diambil kesimpulan bahwa variabel Satuan Pemeriksaan Internal dan Audit Kepatuhan secara bersama-sama atau secara simultan berpengaruh terhadap Terwujudnya Good University Governance. Hal ini dapat diartikan bahwa semakin besar Peran Satuan Pemeriksaan Internal dan Audit Kepatuhan pada Perguruan Tinggi Berstatus PK-BLU dapat meningkatkan terwujudnya Good University Governance.

Hasil penelitian ini diharapkan dapat menjadi bahan pertimbangan bagi Satuan Pemeriksaan Internal untuk lebih meningkatkan perannya dalam menerapkan prinsip-prinsip Audit Kepatuhan pada perguruan tinggi, agar tercapainya Good University Governance. Penelitian ini tentunya masih banyak terdapat kekurangan, dengan demikian dapat menjadi peluang bagi peneliti untuk meneliti lebih luas, misalnya menambahkan variabel-variabel lainnya. Penelitian ini juga diharapkan dapat menjadi acuan bagi penelitian selanjutnya.

\section{DAFTAR PUSTAKA}

(1) Astuti, R. (2010). Modul Praktikum Komputer Lanjut: Analis Deskriptif dan Analitik. Semarang, Indonesia: Universitas Muhammadiyah Semarang

(2) Forest, J. J. F \& Altbach, P. G. (2007). International Handbook of Higher Education. Dordrecht, Netherlands: Springer

(3) Ghozali, I. (2013). Aplikasi Analisis Multivariate Dengan Program SPSS. Semarang, Indonesia: Badan Penerbit Universitas Dipenogoro

(4) Indriantoro, N \& Bambang, S. (2011). Metodologi Penelitian Bisnis untuk Akuntansi dan Manajemen, Edisi Pertama. Yogyakarta, Indonesia: BPFE Yogyakarta

(5) Jansen, M. C., \& Meckling, W. H. (1976). Theory of the Firm: Managerial Behavior, Agency Costs and Ownership Structure. Journal of Financial Economics, 3(4), 305360. https://doi.org/10.1016/0304-405X(76)90026-X 
(6) Kumaat, V. G. (2011). Internal Audit. Jakarta, Indonesia: Erlangga

(7) Mardiasmo. (2005). Akuntansi Sektor Publik. Yogyakarta, Indonesia: Andi Publisher

(8) Puspitasari, N. D. (2012). Peran Satuan Pengawasan Internal dalam Pencapaian Good University Governance Pada Perguruan Tinggi Berstatus PK-BLU. Jurnal UNES, 1(2), 1-8. https://journal.unnes.ac.id/sju/index.php/aaj/article/view/706

(9) United Nations Development Programme. (1997). Governance for sustainable human development / Community Organization Training and Research Advocacy Institute (CO-TRAIN) in cooperation with the United Nations Development Programme (UNDP)-Philippines. Philippines. UNDP Press.

https://digitallibrary.un.org/record/261618? $\mid \mathrm{n}=\mathrm{en}$

(10) Sitompul, A. (2004). Penawaran Umum dan Permasalahannya. Bandung, Indonesia: Citra Aditya Bakti.

(11) Sugiyono. (2010). Metode Penelitian Kuantitatif Kualitatif dan R\&D. Bandung, Indonesia: Alfabeta

(12) Sukirman. (2011). Peran Internal Audit dalam Upaya Mewujudkan Good University Governance di Unnes. Jurnal Dinamika Akuntansi, (4), 64-71. https://journal.unnes.ac.id/nju/index.php/jda/article/view/1961

(13) Wijatno, S. (2009). Pengelolaan Perguruan Tinggi Secara Efisien, Efektif, Dan Ekonomis Untuk Meningkatkan Penyelenggaraan Pendidikan Dan Mutu Lulusan. Jakarta, Indonesia: Salemba Empat

(14) Wolfensohn, J. (1999). Corporate Governance. Financial Times. 